\title{
Towards understanding corrosion initiation in concrete - influence of local concrete properties in the steel-concrete interfacial zone
}

\author{
Carolina Boschmann Käthler ${ }^{1, *}$, Ueli M. Angst ${ }^{1}$, and Bernhard Elsener ${ }^{1,2}$ \\ ${ }^{1}$ ETH Zurich, Institute for Building Materials (IfB), ETH Hönggerberg, 8093 Zurich, Switzerland \\ ${ }^{2}$ University of Cagliari, Department of Chemical and Geological Science, 09100 Cagliari, Italy
}

\begin{abstract}
Chloride-induced corrosion is the most common deterioration process for reinforced infrastructure objects. Improving the understanding of the conditions for initiation of localized corrosion is urgently needed. Research is focused on the influence of "defects" at the steel-concrete interface ( $\mathrm{SCI}$ ), as these weak points might be responsible for corrosion initiation. In contrast to numerous studies with "lab concrete", this study reports results from reinforced concrete cores drilled from old infrastructure objects containing a non-corroding rebar. In contrast to laboratory studies, this guarantees real conditions at the SCI comprising also irregularities such as air voids, plastic settlement voids, cracks, etc. This allows to study chloride-induced corrosion in real conditions - and to determine the so-called "critical chloride content" $C_{\text {crit. }}$ Visual inspection of the SCI enables to establish (or not) influences of the local conditions at the SCI and $C_{\text {crit. }}$ It was found that $C_{\text {crit }}$ strongly decreased with the carbonation depth, even if the carbonation front had not reached the steel. Moreover, coarse air voids and cracks were in this study not particularly susceptible sites for corrosion initiation.
\end{abstract}

\section{Introduction}

One of the main deterioration mechanisms for reinforced concrete infrastructure is chloride-induced corrosion due to the use of de-icing salts or marine environment exposure. The so-called critical chloride content $C_{\text {crit }}$ is the established parameter for predicting whether corrosion initiates or not. The local properties at the steel-concrete interface (SCI) are known to greatly influence $C_{\text {crit. }}$. Further well-known influencing factors are the $\mathrm{pH}$ of the pore solution and the steel potential [1, 2]. While the latter can be reproduced and controlled well in laboratory experiments, mimicking realistic SCI's in laboratory made samples is difficult or even impossible [3].

As $C_{\text {crit }}$ is widely determined in lab-produced samples, the SCI might not be applicable to practice and thus, also the applicability of $C_{\text {crit }}$ to engineering conditions is questionable [2]. To obtain practice-related data for $C_{\text {crit }}$, for instance as input parameters for service life modelling, there is thus a need to measure $C_{\text {crit }}$ on samples from structures.

In this study, $C_{\text {crit }}$ was measured in samples taken from different reinforced concrete structures in Switzerland. After corrosion initiation, the SCI was investigated and related influences were analysed in the context of the obtained $C_{\text {crit. }}$. Additionally, the influences of the carbonation depth and the steel potential (before corrosion initiation) are discussed.

\section{Materials and methods}

\subsection{Sampling on site}

To obtain samples with real conditions at the steelconcrete interface, drilling cores with a diameter of $150 \mathrm{~mm}$ were extracted from three structures in the Swiss Alps (Table 1).

The drilling cores containing one centrally located reinforcement steel were taken from non-corroding regions within the structure. All structures were built with CEM I, which was the most common type of cement used in Switzerland up to the 1990s.

\subsection{Sample preparation in the lab}

The cover depth of each drilling core was reduced to 15$20 \mathrm{~mm}$ to accelerate the chloride ingress during laboratory testing. To avoid corrosion at the steel bar ends, concrete was gently removed at the rebar ends and replaced with a highly-alkaline and dense repair mortar (Fig. 1). Before placing the repair mortar, a self-tapping screw, with cable, and cable lug was fixed to guarantee a durable electrical connection to the steel (Fig. 1).

* Corresponding author: cboschmann@ifb.baug.ethz.ch 
Table 1. Investigated members of reinforced concrete structures and orientation of reinforcing steel in the drilling cores taken.

\begin{tabular}{|c|c|c|c|c|}
\hline Structure & $\begin{array}{c}\text { Age } \\
\text { [years] }\end{array}$ & Element & $\begin{array}{c}\text { Reinforce } \\
\text { ment }\end{array}$ & $\begin{array}{c}\text { drilling } \\
\text { cores }\end{array}$ \\
\hline 1 - Tunnel & 40 & ceiling & horizontal & 11 \\
\hline \multirow{2}{*}{2 - Tunnel } & \multirow{2}{*}{34} & $\begin{array}{c}\text { side wall } \\
1\end{array}$ & vertical & 6 \\
\hline & & $\begin{array}{c}\text { side wall } \\
2\end{array}$ & vertical & 6 \\
\hline \multirow{2}{*}{3 - Bridge } & \multirow{2}{*}{50} & \multirow{2}{*}{$\begin{array}{c}\text { abutment } \\
\text { wall }\end{array}$} & vertical & $10 / 6^{*}$ \\
\hline & & & horizontal & $10 / 4^{*}$ \\
\hline
\end{tabular}

* so far, only 6 and 4 out of 10 drilling cores have initiated and are therefore considered in this study.

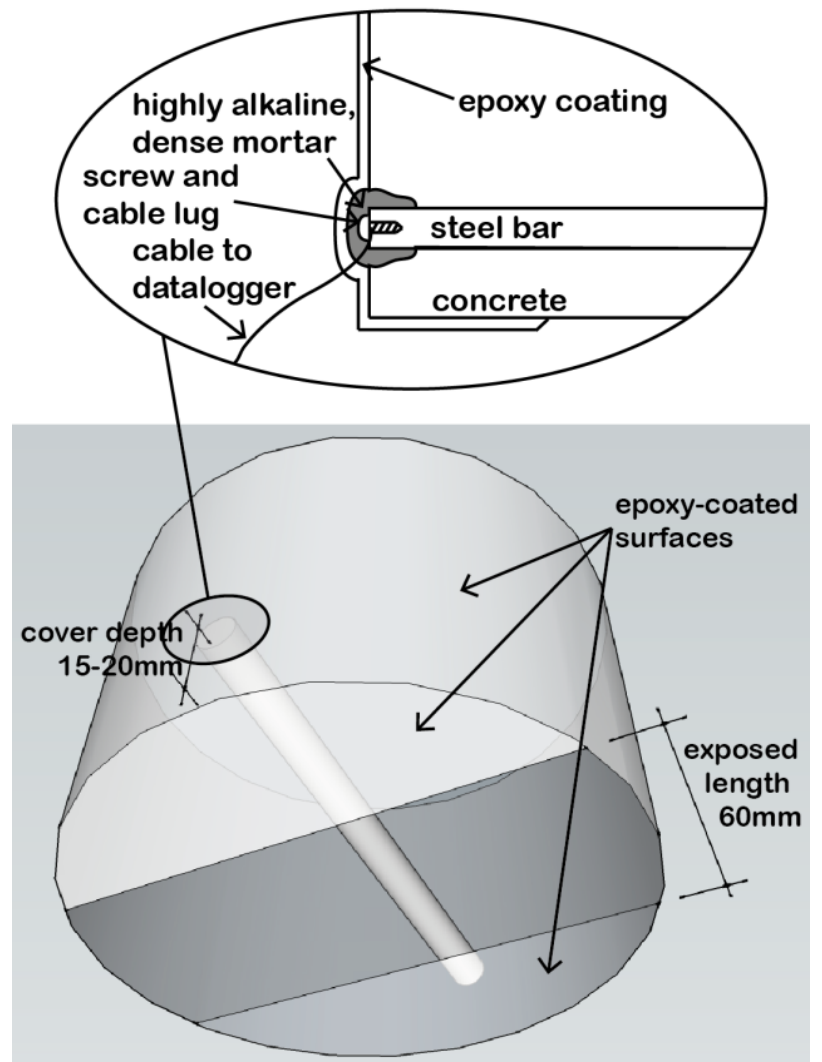

Fig. 1. Prepared drilling core for lab-exposure experiments.

To ensure uniaxial ingress of chlorides, all lateral core surfaces were painted with Epoxy. Also, the exposure side was partially painted with Epoxy (Fig. 1) to avoid any edge effect (viz. corrosion at the steel bar ends). This reduced the exposed surface to a length of $60 \mathrm{~mm}$. A more detailed description of the method can be found in [4].

\subsection{Exposure test}

The prepared drilling cores were connected to a data logger measuring potentials and exposed to water for one week. The exposed surface of the drilling cores is submerged to the exposure solution with a depth of $5 \mathrm{~mm}$. Steel potentials were continuously measured with a reference electrode in the solution $\left(\mathrm{Ag} / \mathrm{AgCl} \mathrm{sat}_{\mathrm{s}}\right)$.

Once stable potentials were achieved, indicating passive steel, the NaCl-content in the solution was increased to $3.5 \%$. The steel potentials were continuously monitored in order to detect corrosion initiation. Corrosion initiation was defined as a drop of potential of at least $150 \mathrm{mV}$ within $24 \mathrm{~h}$ and remaining stable at this lower level for minimum $7 \mathrm{~d}$ [4]. At corrosion initiation the samples were removed from solution.

If no corrosion initiated within a period of approx. 2 months, the $\mathrm{NaCl}$-content was increased to $7 \%$. If no corrosion initiated during the coming 2 months, the $\mathrm{NaCl}$-content was increased to $10 \%$ and kept constant for the further test until all samples showed corrosion initiation.

\subsection{Measuring the critical chloride content}

To measure the chloride content at the level of the reinforcement after corrosion initiation, the samples were split and the concrete powder at the level of reinforcement was collected (Fig. 2). Visual inspection of the SCI to document irregularities was conducted on the steel surface as well as on the imprints in the concrete (two examples in Fig. 2). The location of corrosion initiation was visually identified by corrosion products on the steel surface.

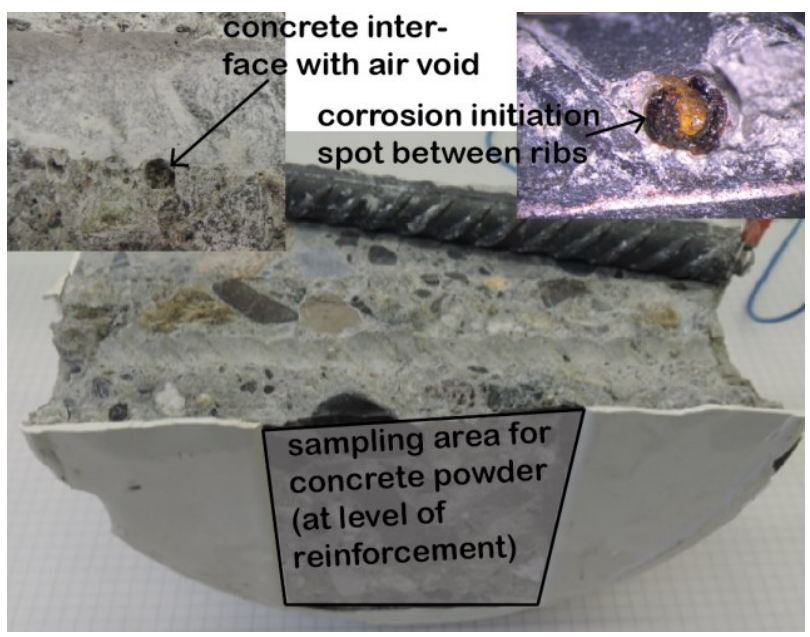

Fig. 2. Split drilling core for determination of chloride concentration and visual inspection of the SCI.

Only irregularities, which could be observed with the naked eye were considered. These were on the concrete surface classified as follows: air void $(\mathrm{V}$, min. diameter approx. $500 \mu \mathrm{m})$, locally higher porosity $(\mathrm{P})$, presence of a tie wire (W), cracks (C), and no irregularities visually detectable $(\mathrm{N})$. The location of corrosion initiation was also marked. An example is depicted in Fig. 3. 


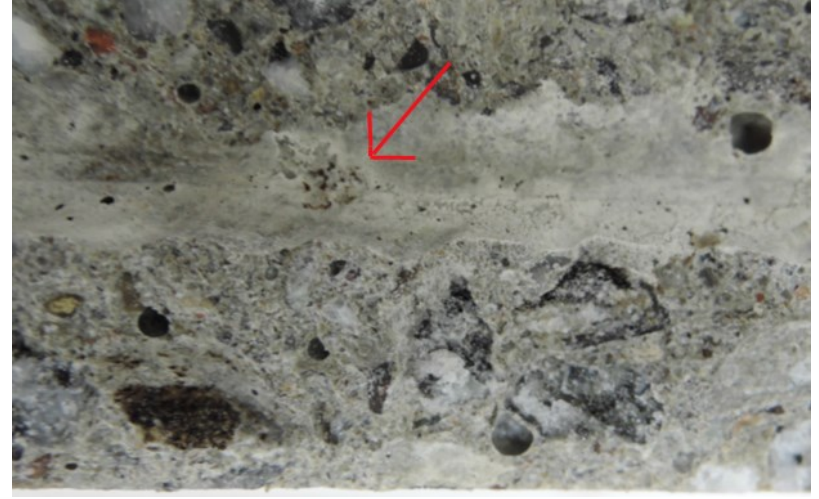

Fig. 3. Examples of irregularities at the SCI: Locally higher porosity (arrow) and small air voids (left part) as well as coarse air voids (right part). Corrosion initiated in this case at the arrow.

Similarly, the location of corrosion initiation at the steel surface was classified as follows: on a rib (R), between two ribs (bR), and adjacent to a rib (aR). aR describes the intersection point where the rib $(\mathrm{R})$ hits the flat part of the steel surface (bR).

After splitting the samples, the carbonation depth was measured with the phenolphthalein spray test. The non-carbonated cover depth was determined as the (original) total cover depth minus the carbonated cover depth (measured at the drilling core). It corresponds thus to the distance between the carbonation front (determined with phenolphthalein) and the steel surface. If the drilling core was not carbonated at all, the minimum non-carbonated cover depth was equal to the cover depth of the drilling core after cutting.

\section{Results and discussion}

\subsection{Influence of local conditions at SCI}

\subsubsection{Concrete surface}

Figure 4 summarizes the measured $C_{\text {crit }}$ for different conditions at the concrete imprint. It is apparent, that most corrosion initiation spots were at locations without any visible irregularities. Only in rare cases did the location of corrosion initiation correspond to visible irregularities at the concrete: locally higher porosity (2 cases), air voids (4 cases), and a tie wire present at the steel ( 1 case). Moreover, the mean $C_{\text {crit }}$ for the samples where no irregularities were found at the location of corrosion initiation was lower than for samples with air voids. Also, all $C_{\text {crit }}$ below $0.65 \%$ by weight of cement were measured for samples which initiated at spots without any irregularities in the concrete $(\mathrm{N})$. As the highest amount of samples were those with no irregularities detectable, their scatter for $C_{\text {crit }}$ is also largest.

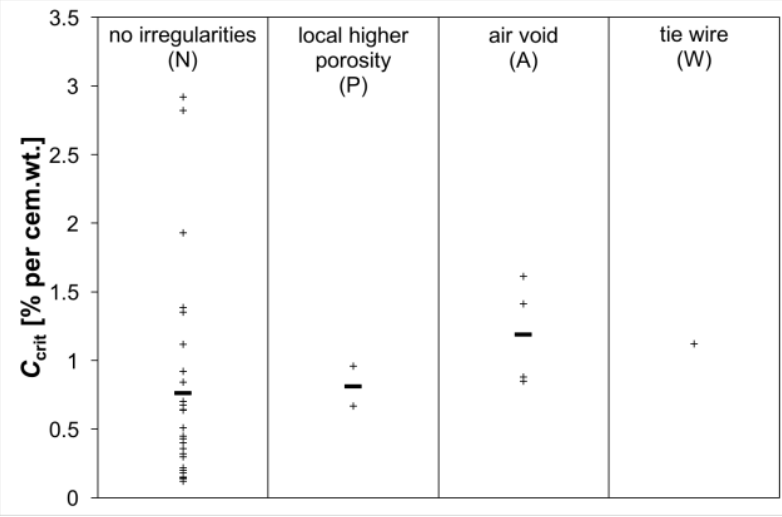

Fig. 4. $C_{\text {crit }}$ for different conditions at SCI for all structures. Black rectangular: mean of $C_{\text {crit }}$ for all structures. The structures are not distinguished as no significant differences were observed between them.

The left pie chart in Figure 5 depicts the total frequency of a corrosion initiation spot at a certain local condition on the concrete surface.

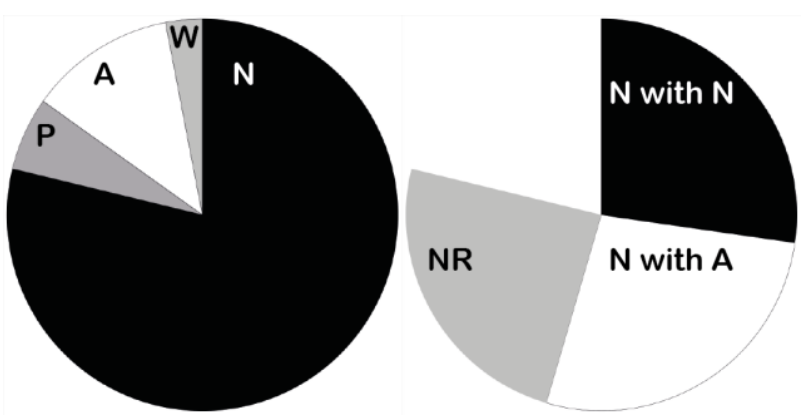

Fig. 5. Left pie chart: Occurrence of initiation at different conditions at SCI for all structures. Right pie chart: The category $\mathrm{N}$ (no irregularities at initiation spot) further divided in: (NR: not reported), see text for explanations.

Figure 5 right shows that samples without defects in the concrete at the corrosion spot can be divided in samples which did not have any visible irregularities over the whole exposed length ( $\mathrm{N}$ with $\mathrm{N})$, and samples showing irregularities, but not where corrosion initiated ( $\mathrm{N}$ with $\mathrm{A}$ ). Interestingly, in one third of the samples where corrosion initiation was not found to correlate with visible irregularities at the SCI, there were actually air voids present at the SCI (elsewhere). This means that for these samples, corrosion initiated preferentially not at air voids or other defects, but at a location without any visible irregularity.

Figure 4 also revealed that in those cases where corrosion actually initiated at air voids, the chloride content needed to trigger corrosion was (on average) higher than when corrosion started at locations without visible irregularities. This may be explained by the moisture content of the samples, i.e. unsaturated. Coarse air voids can only get saturated under prolonged immersion or pressure saturation $[5,6]$. In the presence of air in the voids, initiation of corrosion is hardly possible.

It may also be noted that in 3 samples, there were cracks present at the SCI, but in none of these cases, the 
location of corrosion initiation corresponded to these cracks.

\subsubsection{Steel surface}

Figure 6 depicts the measured $C_{\text {crit }}$ classified according to the location of corrosion initiation with respect to the rebar geometry $(\mathrm{R}$ - initiation on a rib, $\mathrm{aR}$ - adjacent to a rib, bR - between the ribs). In contrast to the results shown in section 3.1.1, these results were found significantly different for the different structures.

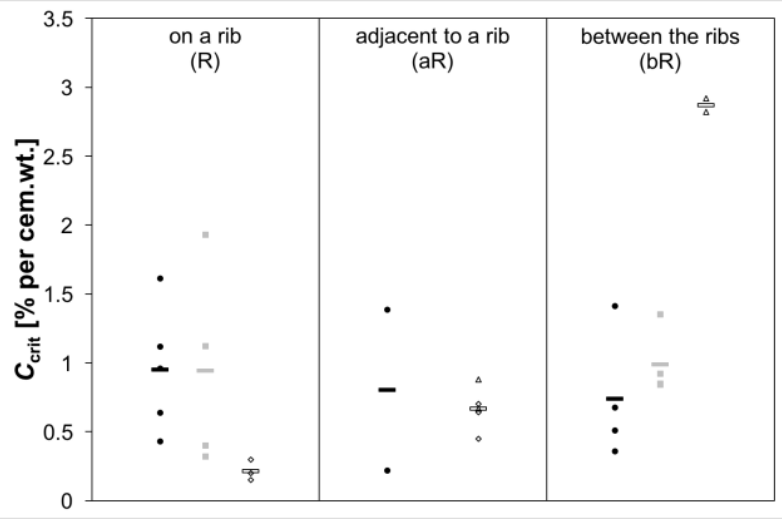

Fig. 6. $C_{\text {crit }}$ depending on the location of corrosion initiation on the rebar geometry. Each structure is depicted on its own: Black circle: Tunnel 1, Grey square: Tunnel 2, White triangular and rhombus: Bridge 3 vertical and horizontal, respectively. The rectangular depicts the mean per structure.

Tunnel 1 (black circles in Fig. 6) and tunnel 2 (grey squares in Fig. 6) show similar results. There are no statistically significant differences for $C_{\text {crit }}$ depending on the location of corrosion initiation with respect to the rebar geometry. Similar $C_{\text {crit }}$ were measured for all three cases (initiation on, between or adjacent to ribs). However, for structure 3 (Bridge, white triangular and rhombus in Fig. 6) this appeared to have a marked influence. Considerably higher $C_{\text {crit }}$ were measured when corrosion initiated between the ribs compared to locations adjacent to ribs. The lowest $C_{\text {crit }}$ were measured when corrosion initiation on ribs.

For horizontal rebars (rhombus in Fig. 6), the $C_{\text {crit }}$ tends to higher values, in contrast to the vertical rebars (triangular in Fig. 6). As the investigations of the samples with vertical and horizontal rebars is on-going, this will further be investigated.

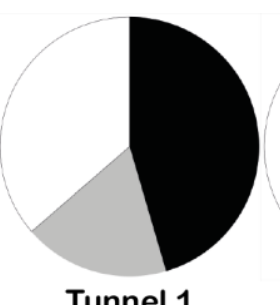

Tunnel 1

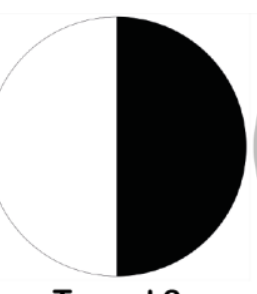

Tunnel 2

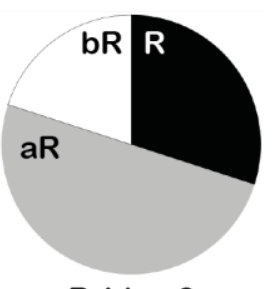

Bridge 3
Fig. 7. Occurrence of initiation at different conditions at SCI per structure. R: initiation spot on a rib, aR: initiation spot adjacent to a rib, bR: initiation spot between the ribs.
This is in line with the results depicted in Figure 7, showing a higher frequency of initiation in the region of rib for bridge 3 than for tunnel 1. For tunnel 2, no initiation spot adjacent to a rib was detected.

The bridge was constructed 10 years before tunnel 1 , which means in 1967. At around 1980, the production of reinforcement in Europe changed from hot-rolled and cold-worked to thermo mechanically strengthened steel. both showing different microstructure over the cross section. The classical hot-rolled and cold-worked reinforcement has a rather homogeneous microstructure over the cross section (ferrite-pearlite). Thermomechanically strengthened steel has a more complex microstructure over the cross section (core: ferritepearlite, surface layer: tempered martensite) [3]. Previous research has indicated that this may have an influence on the susceptibility to corrosion initiation in concrete [7]. Metallurgical investigations are currently under work and may provide a possible explanation for the different behaviour of structure 3 compared to structures 1 and 2.

The influence of the rebar geometry on preferential sites for corrosion (Fig. 7) and on $C_{\text {crit }}$ (Fig. 6) may be explained by properties of both the steel and the concrete. A current study presented at this conference [8] using local electrochemical measurements [9] has revealed large differences in electrochemical properties of the steel surface between locations on or between ribs. Local concrete properties may also be influenced by the rebar geometry for instance regions of plastic settlement below a rib (vertical rebars), which, similar to the bleedwater zone below horizontal bars [10-13], may promote corrosion initiation [14].

\subsection{Influence of non-carbonated cover depth}

Figure 8 shows the relationship between non-carbonated cover depth and measured $C_{\text {crit. }}$. The thicker the noncarbonated cover depth is, the higher is the measured $C_{\text {crit. }}$ If the whole cover depth of the drilling core was not carbonated, the non-carbonated cover depth was marked as a minimal value.

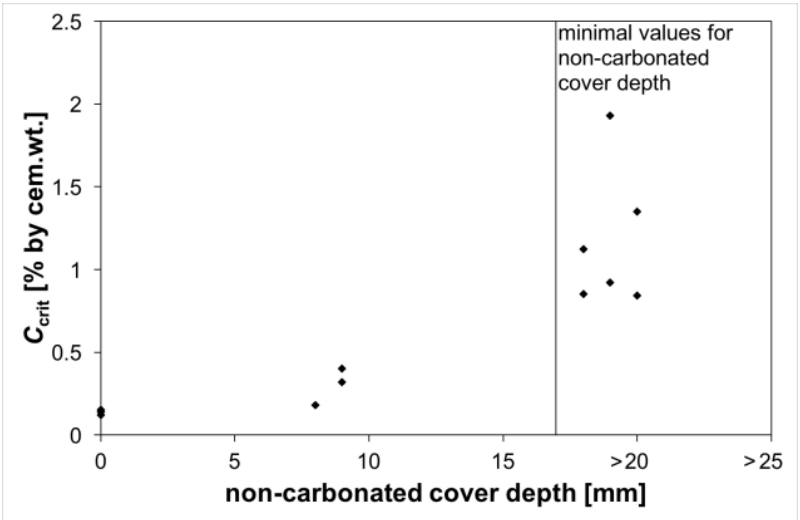

Fig. 8. Influence of carbonation depth on $C_{\text {crit. }}$ The noncarbonated cover depth is the distance between the carbonation front (determined with phenolphthalein) and the steel surface. Data from structure 2. 
This influence of the distance between carbonation front and steel surface can be explained as follows. The $\mathrm{pH}$ of the pore solution is decreasing not immediately from a non-carbonated $(\mathrm{pH}>13)$ to a fully carbonated state ( $\mathrm{pH}=$ approx. 9). This decrease is stepwise [15], showing a first drop in $\mathrm{pH}$ from $>13$ to approx. 12.5 (Portlandite buffer), followed by further decreases down to approx. $\mathrm{pH}$ 9. This means that ahead of the carbonation front associated with $\mathrm{pH} 9$ (phenolphthalein test), there is another front that corresponds to a $\mathrm{pH}$ of approx. 12.5. A recent study using a novel $\mathrm{pH}$ sensor has revealed that this front $(\mathrm{pH} 12.5)$ can be significantly ahead of the "conventional" carbonation front $(\mathrm{pH} 9)$ [15]. Thus, the thickness of non-carbonated concrete cover can be regarded as a first-hand estimate of the $\mathrm{pH}$ of the pore solution at the level of reinforcement: The thicker the non-carbonated cover depth, the higher is the expected $\mathrm{pH}$ of the pore solution at the level of the reinforcement. As corrosion initiation for chlorideinduced corrosion is not only dependent on the chloride content but also on the chemistry of the pore solution, the changing $\mathrm{pH}$ influences clearly the $C_{\text {crit }}[16]$.

Additionally, the ratio between bound and free chlorides is changing with changing $\mathrm{pH}$, i.e. with decreasing $\mathrm{pH}$ more bound chlorides will be released [17]. As more free chlorides are available for a closer carbonation front, corrosion initiation will more readily occur for the same total chloride content.

\subsection{Influence of steel potential}

Before being exposed to chlorides, the steel potential in concrete was measured. It varied in the range from $150 \ldots+50 \mathrm{mV}$ vs $\mathrm{Ag} / \mathrm{AgCl}_{\text {sat }}$. During exposure to solutions, the potentials stayed in the same range until corrosion initiation. No correlation between these steel potentials and $C_{\text {crit }}$ were found in this study (Figure 9).

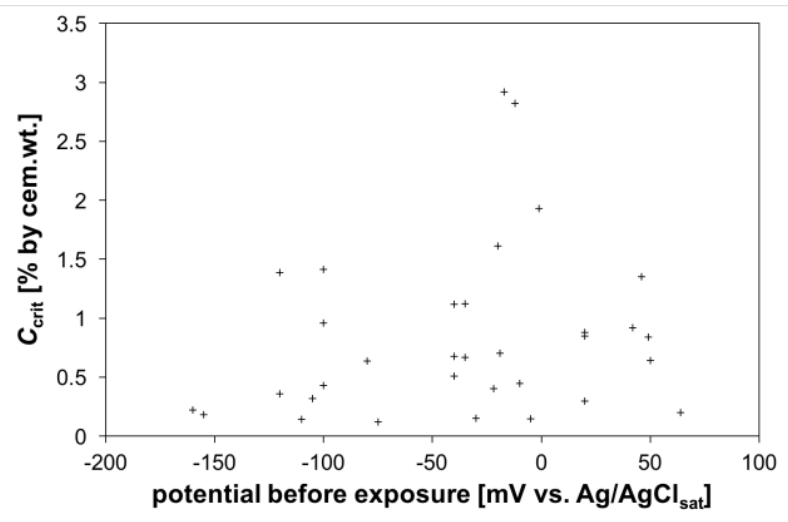

Fig. 9. No correlation between steel potential and $C_{\text {crit. }}$

This is in accordance with [18], where potentials between -200 to $+50 \mathrm{mV}$ vs. SCE had no significant influence on $C_{\text {crit }}$; only potentials lower than $-200 \mathrm{mV}$ vs. SCE influenced $C_{\text {crit. }}$ Such low potentials were not measured within this study.

\section{Conclusion}

From this study the following can be concluded:

- Visible irregularities at the steel-concrete interface (SCI) such as cracks or air voids are not particularly susceptible sites for corrosion initiation during immersion in chloride containing solutions for several month. In many cases, corrosion started at locations where no irregularities were visually detected at the SCI - despite the presence of coarse air voids or cracks at the SCI. Additionally, $C_{\text {crit }}$ was on average higher when corrosion started at air voids than when corrosion initiated at locations where no irregularities were visible.

- The carbonation depth was found to play a role on corrosion initiation even if the carbonation front (phenolphthalein) has not yet reached the steel surface. $C_{\text {crit }}$ was significantly depressed (by a factor of 2-3) when the carbonation front had approached the steel to less than $10 \mathrm{~mm}$, compared to when the carbonation front was still $>15 \mathrm{~mm}$ away from the steel.

- In one structure, there was a significant tendency for corrosion to initiate on the ribs of the reinforcing steel rather than between the ribs. In the two other structures, no significant influence of the rebar geometry on the location of corrosion initiation was found.

- The steel potential was within a range of $-150 \ldots+50 \mathrm{mV}$ vs $\mathrm{Ag} / \mathrm{AgCl}_{\text {sat }}$. In this range, the potential had no significant influence on $C_{\text {crit. }}$.

The authors acknowledge the Federal Roads Office of Switzerland for financing this research project.

\section{References}

1. L. Bertolini, B. Elsener, P. Pedeferri, E. Redaelli, and R. Polder, Corrosion of steel in Concrete Prevention, Diagnosis, Repair. 2nd ed., Weinheim: Wiley-VCH (2013)

2. U. Angst, B. Elsener, C.K. Larsen, and $\varnothing$. Vennesland, Cem. Concr. Res. 39, (2009)

3. U.M. Angst, M.R. Geiker, A. Michel, C. Gehlen, H. Wong, O.B. Isgor, B. Elsener, C.M. Hansson, R. François, K. Hornbostel, R. Polder, M.C. Alonso, M. Sanchez, M.J. Correia, M. Criado, A. Sagüés, and N. Buenfeld, Mater. Struct. 50, (2017)

4. U.M. Angst, C. Boschmann, M. Wagner, and B. Elsener, J. Vis. Exp. 126, (2017)

5. K. Eriksen, M. Geiker, B. Grelk, P. Laugesen, E.J. Pedersen, N. Thaulow, P. Goldman, and J.O. Frederiksen, Method for Test of the Frost Resistance of High Performance Concrete. Performance testing versus in situ observations. 1996.

6. G. Fagerlund, The long time water absorption in the air-pore structure of concrete. 1993.

7. U.M. Angst and B. Elsener. in ICCRRR. 2015. Leipzig (D): CRC Press. 
8. L. Michel and U.M. Angst. in ICCRRR. 2018, in preparation. Cape Town.

9. M. Stefanoni, U. Angst, and B. Elsener, Corros Sci. 98, (2015)

10. A.T. Horne, I.G. Richardson, and R.M.D. Brydson, Cem. Concr. Res. 37, (2007)

11. T.U. Mohammed, N. Otsuki, H. Hamada, and T. Yamaji, ACI Materials Journal. 99, (2002)

12. T.A. Soylev and R. François, Cem. Concr. Res. 33, (2003)

13. R.J. Zhang, A. Castel, and R. François, Magazine of Concrete Research. 63, (2011)
14. L. Yu, R. François, V.H. Dang, V. L'Hostis, and R. Gagné, Cem. Concr. Res. 67, (2015)

15. Y. Seguí Femenias, U. Angst, and B. Elsener, RILEM Technical Letters. 2, (2017)

16. G.K. Glass and N.R. Buenfeld, Corros Sci. 39, (1997)

17. G.K. Glass, B. Reddy, and N.R. Buenfeld, Corros Sci. 42, (2000)

18. C. Alonso, M. Castellote, and C. Andrade, Electrochimica Acta. 47, (2002) 